2

3 Preface - Addressing challenges to advance sediment fingerprinting research 4

5 Hugh G. Smith • Olivier Evrard • William H. Blake • Philip N. Owens

6

7 Received: 27 July 2015 / Accepted: \#\# July 2015

8 (C) Springer-Verlag Berlin Heidelberg 2015

9

10
H. G. Smith ( $ه)$

School of Environmental Sciences, University of Liverpool, Liverpool, L69 7ZT, UK

\section{O. Evrard}

Laboratoire des Sciences du Climat et de l'Environnement (LSCE), Unité Mixte de Recherche 8212 (CEA-CNRS-UVSQ/IPSL), Gif-sur-Yvette, Cedex, 91198, France

W. H. Blake

School of Geography, Earth and Environmental Sciences, Plymouth University, Plymouth, PL4 8AA, UK

P. N. Owens

Environmental Science Program \& Quesnel River Research Centre, University of Northern British Columbia, Prince George, British Columbia, V2N 4Z9, Canada

Hugh G. Smith

e-mail: $\underline{\text { Hugh.Smith@liverpool.ac.uk }}$

\section{$(\bowtie)$ Corresponding author:}




\section{Background}

Scientists and managers require information on the patterns and processes associated with fine sediment and related contaminant dynamics in river catchments. A fundamental part of this understanding of contemporary river systems relates to the sources of fine sediment mobilised, transported and temporarily stored in river catchments. Such information is particularly sought after because it has considerable value for the targeting of management resources to reduce excess fine sediment supply and its very significant impacts on water resources and aquatic ecosystems (Owens et al. 2005; Bilotta and Brazier 2008). Sediment source information is also needed to complement other measurement or modelling techniques used in catchment-scale studies of fine sediment and associated contaminant redistribution (Evrard et al. 2011; Smith et al. 2011).

Fine sediment source fingerprinting procedures have significant potential to address these requirements. Referred to henceforth as 'sediment fingerprinting', this technique involves the discrimination of sediment sources and apportionment of contributions from those sources to fine-grained sediment (typically $<63 \mu \mathrm{m}$ ) transported within river catchments. The approach requires the selection of physical and chemical tracer properties that discriminate source materials combined with the use of statistical procedures to un-mix the unknown contributions from these sources to the mixture of sediment delivered downstream. Catchment sources widely considered by sediment fingerprinting studies include agricultural land uses, geological zones and subsoil sources (e.g. channel banks, gullies), as well as specific features such as road verges, urban surfaces and farm tracks. To discriminate these sources, a diverse range of tracer properties may be employed, comprising geochemical, radionuclide, mineral magnetic, stable isotopes, organic compounds, and colour properties (Foster and Lees 2000; Guzman et al. 2013).

Sediment fingerprinting originated from studies into the use of mineral magnetic and geochemical properties as source tracers in the 1970s and 1980s and has since expanded rapidly (see the review by Walling 2013). Some studies focused on the use of pre-selected tracer properties that were known to discriminate targeted sources, such as fallout radionuclides (Wallbrink and Murray 1993). In contrast, multi-tracer sediment fingerprinting studies rely on statistical selection of a subset of tracer properties that discriminate sources. Approaches to address uncertainty in predicted source contributions based on Monte Carlo 
sampling methods were also developed (Franks and Rowan 2000) and became an important part of the sediment fingerprinting procedure. Early fingerprinting studies focused on land use and channel bank sources in agricultural catchments (Peart and Walling 1986; Walling 1993). The subsequent growth of sediment fingerprinting research extended applications across a range of catchment sizes, sediment sources and environments, including urban and forest settings. However, agricultural catchments remain the dominant environment for sediment fingerprinting studies, reflecting the demand from management agencies for information to support measures for reducing sediment pollution from agriculture (Gellis and Walling 2011).

Against this background, this special issue of the Journal of Soils and Sediments on 'Advances in Sediment Fingerprinting' was conceived to bring together a set of publications at the forefront of recent developments across this field of research. The papers were largely drawn from the session HS9.7 'Revisiting techniques for quantifying sources and travel times of fine sediment from catchment to coast' which was held during the European Geosciences Union (EGU) General Assembly in 2014. This followed a similar previous session held during the EGU Assembly in 2013. The impetus for the organisation of these sessions originated from discussions between the authors of this preface and others concerning challenges and progress in the development of sediment fingerprinting techniques.

\section{Challenges}

Over the last 40 years, very considerable progress has been made in the development of sediment fingerprinting techniques. However, in the previous two years, there has been a move to challenge and test underlying assumptions of the fingerprinting technique along with aspects of data processing and the treatment of uncertainty. This has been in response to studies that present sediment fingerprinting as a highly transferable technique that delivers accurate and precise estimates of source contributions across a range of environments. In contrast, recent findings suggest that such a view of the present state of sediment fingerprinting as a fully functioning scientific and management tool is misplaced. Here, we briefly review contributions from this special issue and the wider literature that address these recent challenges.

\subsection{Source and sediment sampling}


Combining independent sources of information may have particular value for the design of source and sediment sampling protocols used by sediment fingerprinting studies. For example, Wilkinson et al. (2015, this issue) employed modelling of soil erosion across a large catchment to guide stratified sampling of surface soils to reflect the disproportionate effect that highly eroding areas will exert on the concentrations of tracers used to characterise surface sources. Wethered et al. (2015, this issue) demonstrated the value of coupling sediment source tracing with geomorphic analysis based on various channel metrics to understand downstream changes in sediment contributions from topsoil and subsoil sources. The investigation of longitudinal changes in sediment source contributions was also an important part of the study by Palazón et al. (2015, this issue), while Haddadchi et al. (2015, this issue) found that, within the 18 month timescale of their study, proximal sources tended to make a higher contribution to a given river sampling point than more distal sources in a nested catchment study based on geological source areas. The large reported changes in proportional source contributions with distance downstream were attributed to changes in land use, erosion processes and the effect of sediment storage opportunities in reducing the proportion of upstream sediments that reached downstream measurement sites. The findings from these various studies show that selection of both the source and sediment sampling locations within catchments can have important implications for the interpretation of results from sediment fingerprinting studies.

\subsection{Source discrimination and tracer selection}

Recent criticisms of sediment fingerprinting draw attention to the use of statistical procedures to select tracer properties without identifying the basis for source discrimination. Careful consideration of the factors leading to source discrimination, whether by pedogenic, anthropogenic or other environmental processes, is required to support the selection of tracers used to discriminate sources, in addition to statistical methods (Koiter et al. 2013a; Smith et al. 2013; Smith and Blake 2014). Effective source discrimination relies on differences between sources exceeding those differences that may result from other landscape factors affecting soil properties (Smith and Blake 2014). Small contrasts between tracer concentrations in different sources were observed to correspond with larger uncertainty in source apportionment results (Pulley et al. 2015), emphasising the importance of tracer selection for predicting source contributions with confidence. 
A major theme of studies in the special issue relates to tracer selection. The standard approach for selecting tracers seeks to minimise the number of tracers for use in source unmixing. Sherriff et al. (2015, this issue) found that uncertainty in source predictions was actually reduced by increasing rather than minimising the number of tracers used in source un-mixing. Laceby et al. (2015, this issue) used prior geochemical knowledge of geological source areas and statistical processing as a basis for element selection, in contrast to many previous fingerprinting studies that rely of statistical analysis alone. In some instances, the two approaches selected different elements which led to divergent source apportionment results. Pulley et al. (2015, this issue) compared predicted source contributions based on data from radionuclide, geochemical and mineral magnetic tracer groupings and found large differences in source predictions between groups. These studies clearly demonstrate that the choice of tracers can exert an important effect on predicted source contributions.

\subsection{Tracer non-conservative behaviour}

Non-conservative behaviour of tracer properties during transport and storage can confound sediment fingerprinting studies and requires attention (Koiter et al. 2013b). The non-conservative behaviour of even a single tracer property included in source un-mixing may result in large changes to predicted source contributions, as was shown by Sherriff et al. (2015, this issue) using synthetic data. This effect on source contributions was found to be greatly reduced by increasing the number of tracer properties used for un-mixing. Kraushaar et al. (2015, this issue) adopted an expanded tracer selection procedure for fingerprinting reservoir sediments to reduce the possible effect of non-conservative behaviour. In addition to statistical selection, this approach combined a literature review with analysis of reservoir water chemistry to identify tracers that may be susceptible to dissolution during transport from the terrestrial to the aquatic environment. Few sediment fingerprinting studies explicitly account for such changes in environmental conditions that may affect the conservative behaviour of selected tracer properties.

The sensitivity of tracer concentrations and predicted source contributions to nonconservative behaviour of particle size and organic matter content has been a focus of recent work (Koiter et al. 2013a; Smith and Blake 2014). Differences between sources and downstream sediments may arise from selective transport, the effect of which was captured quantitatively by Koiter et al. (2015, this issue) using a flume experiment to show that 
increasing channel gravel depth led to preferential deposition of larger particles. Haddadchi et al. (2015, this issue) highlighted the important effect that particle size can exert, with predicted source contributions varying between three size fractions analysed. These authors emphasised the significance of identifying the size fraction of most interest as part of sediment fingerprinting studies, the selection of which should be guided by the research or management problem under investigation.

\subsection{Mixing models and data treatments}

The type and structure of statistical mixing models used in sediment fingerprinting can significantly impact on source apportionment results, a point largely overlooked in the fingerprinting literature until recently. The emergence of Bayesian mixing models in sediment fingerprinting (e.g. Fox and Papanicolaou 2008; D’Haen et al. 2013; Nosrati et al. 2014) represents a departure from the widely employed frequentist based approaches, which typically use optimization to minimize the sum of squared residuals to obtain predictions of catchment source contributions (e.g. Collins et al. 1997). The study by Cooper et al. (2014) showed that the choice of mixing model can significantly affect estimates of source contributions, with variations in median contributions of up to $21 \%$ between tested model versions, which included both Bayesian and frequentist model structures. Likewise, Haddadchi et al. (2014) found considerable variation in source apportionment results from various mixing model formulations compared to data from artificial mixtures. Notably, the least accurate model tested by these authors was that which applied weightings to tracer data.

Various correction factors and weightings have often been employed in mixing models. Correction factors have been used to account for differences in particle size and organic matter content between sources and target sediments (e.g. Collins et al. 1997). Tracer-specific weightings have also been applied based on relative differences in: (i) the proportion of sources classified correctly using Discriminant Function Analysis; and (ii) the level of within-source variability for individual tracer properties (e.g. Collins et al. 2010). These weightings were intended to ensure tracers with higher discriminatory power or lower with-in source variability exerted a greater influence during the optimisation procedure used to obtain predictions of source contributions. 
The use of these correction factors and weightings has since been challenged in the literature. Smith and Blake (2014) found that inconsistent relationships between particle size, organic matter content and tracer concentrations undermined the basis for the use of widely applied correction factors. They recommended against the use of organic matter corrections, while corrections for particle size should be considered on a case-by-case basis. Laceby and Olley (2014) used artificial mixtures of catchment sources to test the effect of different data treatments on source apportionment. These authors found that the use of tracer weightings did not improve the accuracy of source apportionment results, and in the case of the weighting based on within-source variability, actually significantly reduced the accuracy of results compared to known artificial mixtures. It follows that a transparent and data-based justification is required to support any changes or weightings that are applied to tracer datasets used in source un-mixing.

\section{Recommendations and future needs}

The findings from recent research together with the papers published in this special issue challenge underlying assumptions, data processing and mixing modelling approaches widely used in sediment fingerprinting research. Combined, this highlights a desire by many researchers to address key methodological aspects of sediment fingerprinting to support a renewal of research progress in this field. Ultimately, for sediment fingerprinting research to advance, we need to open the 'black box' linking catchment source inputs to sediment outputs (Koiter et al. 2013b). This prevailing 'black box' also extends beyond the catchment processes affecting tracer development to encompass a severe lack of transparency in aspects of data presentation, processing and caveats that have been a feature of too many sediment fingerprinting papers. Nevertheless, we consider that there has been considerable research progress in the last two years, as revealed by a growing diversity of questions, approaches and groups actively pursuing sediment fingerprinting research. Such diversity can only be of benefit to the field. Here, we outline recommendations and future needs to support the continued development of sediment fingerprinting.

Recent work has clearly established the need to combine both environmental and statistical approaches to tracer selection. Statistical selection of tracers should be complemented by: (i) information on the environmental or anthropogenic basis for source discrimination; and (ii) review of literature pertaining to the selected tracers and the 
likelihood that they may undergo transformations in the study environment (Koiter et al. 2013b; Kraushaar et al. 2015, this issue). Prior to undertaking any statistical treatment of tracer data, the range in source and sediment tracer datasets should be compared to check for evidence of non-conservative behaviour (Martínez-Carreras et al. 2010). This latter point is now a feature of tracer selection in most recent fingerprinting studies.

Statistical tracer selection procedures that minimise the number of tracers passed to the mixing model require re-examination. There is growing evidence to suggest that reducing the number of tracers increases the likelihood of errors in source ascription by allowing a single erroneous tracer to exert a greater influence on predicted source contributions (Sherriff et al. 2015, this issue) or through selection of tracers that may strongly discriminate only a subset of sources (Smith and Blake 2014). The latter may lead to mixing model optimisation that favours those tracers that exhibit the largest differences between some but not necessary all sources. Selecting tracers that maximise contrasts in tracer concentrations between all sources is likely to be an important factor in reducing source prediction uncertainty (Pulley et al. 2015).

Recent work criticised unjustified corrections to tracer data for organic matter content (Smith and Blake 2014) and the use of tracer weightings that actually reduced model accuracy (Laceby et al. 2015). On this basis, corrections for organic matter and tracer weightings based on discrimination ability or within-source variability should not be used in source un-mixing. In contrast, it has been shown that including elemental correlations improves the accuracy of predicted source contributions compared to artificial mixtures (Laceby et al. 2015). Therefore, future studies should consider element correlations as part of the procedure for sampling individual source tracer distributions to ensure that relationships between individual elements are preserved (Laceby et al. 2015).

The choice of mixing model type and structure constitutes a significant future research challenge for sediment fingerprinting. The growth of research investigating the effect of mixing model structure and treatment of uncertainty (cf. Cooper et al. 2014; Nosrati et al. 2014) has opened up a set of choices for source un-mixing, not least of which includes the selection of Bayesian or frequentist mixing model structures. Certainly more work is needed in this area to determine whether there is a preferred approach that can be applied more generally. The use of artificial mixtures would form a useful basis for testing the performance of different model structures and error treatments. 
There are several other aspects of sediment fingerprinting that warrant further attention. Sediment fingerprinting requires pre-identification of all major sources contributing to downstream sediment. Evidence of an un-sampled source may be expected to emerge when comparing source and sediment tracer datasets, however, this cannot be assumed as the un-sampled source may not be captured by the suite of tracers used. Greater justification is needed for the pre-selection of sources in future sediment fingerprinting studies. Another challenge relates to balancing laboratory costs against the data demands of mixing models, particularly Bayesian models that require larger input datasets. The collection of greater sample numbers per source should be seen as desirable, particularly with increasing catchment size and diversity of land use or geology, which are likely to enhance the heterogeneity of physical and chemical properties of source materials, thereby hindering source discrimination. The viability of future studies may hinge increasingly on the need for sampling levels that are commensurate with catchment and source heterogeneity.

\section{Concluding remarks}

The use of the sediment fingerprinting technique to identify the sources of fine sediment (and associated nutrients and contaminants) in river catchments has grown rapidly in the last 5 to 10 years (Koiter et al. 2013b; Walling 2013). This has resulted in scientists from a variety of disciplines new to this field (e.g. inorganic and organic chemistry, ecology, statistics and mathematics), working alongside those from disciplines that have traditionally tackled catchment sediment problems (e.g. soil science, hydrology, geomorphology), to develop new fingerprinting approaches and operational procedures. Interdisciplinary cooperation is vital to increase the robustness of the technique and confidence in model outputs to support catchment managers and policy makers. This is an exciting time for scientists across disciplines to be engaged in sediment fingerprinting and we hope that the discussion above and the papers in this special issue contribute to this growing research momentum.

\section{References}

Billota GS, Brazier RE (2008) Understanding the influence of suspended solids on water quality and aquatic biota. Water Res 42:2849-2861 
Collins AL, Walling DE, Leeks GJL (1997) Source type ascription for fluvial suspended sediment based on a quantitative composite fingerprinting technique. Catena 29:127

Collins AL, Walling DE, Webb L, King P (2010) Apportioning catchment scale sediment sources using a modified composite fingerprinting technique incorporating property weightings and prior information. Geoderma 155:249-261

Cooper RJ, Krueger T, Hiscock KM, Rawlins BG (2014) Sensitivity of fluvial sediment source apportionment to mixing model assumptions: A Bayesian model comparison. Water Resour Res 50:9031-9047

D'Haen K, Verstraeten G, Dusar B, Degryse P, Haex J, Waelkens M (2013) Unravelling changing sediment sources in a Mediterranean mountain catchment: a Bayesian fingerprinting approach. Hydrol Process 27:896-910

Evrard O, Navratil O, Ayrault S, Ahmadi M, Némery J, Legout C, Lefèvre I, Poirel A, Bonté P, Esteves M (2011) Combining suspended sediment monitoring and fingerprinting to determine the spatial origin of fine sediment in a mountainous river catchment. Earth Surface Process Landforms 36:1072-1089

Foster IDL, Lees JA (2000) Tracers in Geomorphology: theory and applications in tracing fine particulate sediments. In: Foster IDL (ed) Tracers in Geomorphology. John Wiley \& Sons Ltd, Chichester, UK, pp 3-20

Fox JF, Papanicolaou AN (2008) An un-mixing model to study watershed erosion processes. Adv Water Resour 31:96-108

Franks SW, Rowan JS (2000) Multi-parameter fingerprinting of sediment sources: uncertainty estimation and tracer selection. In: Bentley LR (ed) Computational Methods in Water Resources XIII. Balkema, Rotterdam, The Netherlands, pp 10671074

Gellis AC, Walling DE (2011) Sediment source fingerprinting (tracing) and sediment budgets as tools in targeting river and watershed restoration programs. In: Simon A, Bennett SJ, Castro JM (ed.) Stream restoration in dynamic fluvial systems: scientific approaches, analyses and tools, Geophysical Monograph Series vol. 194. AGU, Washington D.C., USA, pp 263-291

Guzman G, Quinton JN, Nearing MA, Mabit L, Gómez JA (2013) Sediment tracers in water erosion studies: current approaches and challenges. J Soils Sediments 13:816-833 
Haddadchi A, Olley J, Laceby P (2014) Accuracy of mixing models in predicting sediment source contributions. Sci Total Environ 497-498:139-152

Haddadchi A, Olley J, Pietsch (2015, this issue) Quantifying sources of suspended sediment in three size fractions. J Soils Sediments. doi: 10.1007/s11368-015-1196-1

Koiter AJ, Lobb DA, Owens PN, Petticrew EL, Tiessen K, Li S (2013a) Investigation the role of scale and connectivity in assessing the sources of sediment in an agricultural watershed in the Canadian prairies using sediment source fingerprinting. J Soils Sediments 13:1676-1691

Koiter AJ, Owens PN, Petticrew EL, Lobb DA (2013b) The behavioural characteristics of sediment properties and their implications for sediment fingerprinting as an approach for identifying sediment sources in river basins. Earth Sci Rev 125:24-42

Koiter AJ, Owens PN, Petticrew EL, Lobb DA (2015, this issue) The role of gravel channel beds on the particle size and organic matter selectivity of transported fine-grained sediments: implications for sediment fingerprinting and biogeochemical flux studies. J Soils Sediments. doi: 10.1007/s11368-015-1203-6

Kraushaar S, Schumann T, Ollesch G, Schubert M, Vogel H-J, Siebert C (2015, this issue) Sediment fingerprinting in northern Jordan: element specific correction factors in a carbonatic setting. J Soils Sediments. doi: 10.1007/s11368-015-1179-2

Laceby JP, Olley J (2015) An examination of geochemical modelling approaches to tracing sediment sources incorporating distribution mixing and elemental correlations. Hydrol Process 29:1669-1685

Laceby JP, McMahon J, Evrard O, Olley J (2015, this issue) A comparison of geological and statistica approaches to element selection for sediment fingerprinting. J Soils Sediments. doi: 10.1007/s11368-015-1111-9

Martínez-Carreras N, Udelhoven T, Krein A, Gallart F, Iffly JF, Ziebel J, Hoffmann L, Pfister L, Walling DE (2010) The use of sediment colour measured by diffuse reflectance spectrometry to determine sediment sources: application to the Attert River catchment (Luxembourg). J Hydrol 382:49-63

Nosrati K, Govers G, Semmens BX, Ward EJ (2010) A mixing model to incorporate uncertainty in sediment fingerprinting. Geoderma 217-218:173-180

Owens PN, Batalla RJ, Collins AJ, Gomez B, Hicks DM, Horowitz AJ, Kondolf GM, Marden M, Page MJ, Peacock DH, Petticrew EL, Salomons W, Trustrum NA (2005) Fine-grained 
sediment in river systems: environmental significance and management issues. River Res Applic 21:693-717

Palazón L, Gaspar L, Latorre B, Blake WH, Navas A (2015, this issue) Identifying sediment sources by applying a fingerprinting mixing model in a Pyrenean drainage catchment. J Soils Sediments. doi: 10.1007/s11368-015-1175-6

Peart MR, Walling DE (1986) Fingerprinting sediment sources: the example of a drainage basin in Devon, UK. In: Hadley RF (ed) Drainage Basin Sediment Delivery. IAHS Publication 159, IAHS Press, Wallingford, UK, pp 41-55

Pulley S, Foster I, Antunes P (2015) The uncertainties associated with sediment fingerprinting suspended and recently deposited fluvial sediment in the Nene river basin. Geomorphol 228:303-319

Pulley S, Foster I, Antunes P (2015, this issue) The application of sediment fingerprinting to floodplain and lake sediment course: assumptions and uncertainties evaluation through case studies in the Nene Basin, UK. J Soils Sediments. doi: 10.1007/s11368015-1136-0

Sherriff SC, Franks SW, Rowan JS, Fenton O, Ó’hUallacháin D (2015, this issue) Uncertaintybased assessment of tracer selection, tracer non-conservativeness and multiple solutions in sediment fingerprinting using synthetic and field data. J Soils Sediments. doi: $10.1007 / \mathrm{s} 11368-015-1123-5$

Smith HG, Blake WH (2014) Sediment fingerprinting in agricultural catchments: a critical reexamination of source discrimination and data corrections. Geomorphol 204:177191

Smith HG, Sheridan GJ, Lane PNJ, Noske P, Heijnis H (2011) Changes to sediment sources following wildfire in a forested upland catchment, southeastern Australia. Hydrol Process 25:2878-2889

Smith HG, Blake WH, Owens PN (2013) Discriminating fine sediment sources and the application of sediment tracers in burned catchments: a review. Hydrol Process 27:943-958

Walling DE (2013) The evolution of sediment source fingerprinting investigations in fluvial systems. J Soils Sediments 13:1658-1675

Walling DE, Woodward JC, Nicholas AP (1993) A multi-parameter approach to fingerprinting suspended-sediment sources. In: Peters NE, Hoehn E, Leibundgut Ch, Tase N, Walling 
382

Wallbrink PJ, Murray AS (1993) Use of fallout radionuclides as indicators of erosion processes. Hydrol Process 7: 297-304

Wethered AS, Ralph TJ, Smith HG, Fryirs KA, Heijnis H (2015, this issue) Quantifying fluvial (dis)connectivity in an agricultural catchment using a geomorphic approach and sediment source tracing. J Soils Sediments. doi: 10.1007/s11368-015-1202-7

Wilkinson SN, Olley JM, Furuichi T, Burton J, Kinsey-Henderson AE (2015, this issue) Sediment source tracing with stratified sampling and weightings based on spatial gradients in soil erosion. J Soils Sediments. doi: 10.1007/s11368-015-1134-2 